\title{
ТЕОРЕТИЧЕСКИЕ АСПЕКТЫ СООТНОШЕНИЯ ЧЛЕНСТВА В ООН С ПРИЗНАНИЕМ НОВЫХ ГОСУДАРСТВ
}

\begin{abstract}
Аннотация: В данной статье рассматриваются вопросы соотношения признания новых государств и членства в ООН. Рассматриваются положения Устава ООН и других нормативных актов, а также решений международных органов правосудия. Так, в частности рассматривается решение Международного трибунала для судебного преследования лии, ответственных за серьезные нарушения международного гуманитарного права, совершенные на территории бывщей Югославии, которое свидетельствует не только о том, что в его понимании членство в ООН равносильно признанию того или иного субъекта как нового государства, но и о том, что даже субъект фактически не обладающий независимостью (суверенитетом), но являющийся членом ООН, признается им как государство лишь на том основании, что он является членом данной Организации. По мнению автора такой подход является далеко не реалистичным, так как противоречит сложившейся практике. Автор определяет признание одного государства другим как акт политической воли и выражения суверенитета признающего государства, так как он остается в полной дискреции признающего государства, тогда как принятие в члены ООН является юридическим актом. Выделяется ряд причин по которым членство в ООН не может рассматриваться равносильным коллективному признанию государствами-членами ООН нового государства.

Review: This article is devoted to the issues of correlation between recognition of the new states and the UN membership. The author evaluates the provisions of the UN Charter and other normative acts, as well as the international judicial decisions. In particular, he analyzes the decision of the International Tribunal for Former Yugoslavia (ICTY), showing that the UN membership equals recognition of a subject as new state, as well as that the subject having the UN membership, while not being de facto independent (sovereign), can be recognized as a state due to its membership in this organization. In the opinion of the author such an approach is not realistic, since it contradicts the existing practice. The author defines recognition of one state by the other as an act of political will and expression of sovereignty of a recognizing state, since it remains in the total discretion of a recognizing state, while the UN membership is a legal act. The author points out a number of reasons for which the UN membership cannot be equal to the collective recognition of a new state by the UN Member States. Ключевые слова: понятие государства, практика принятия, члены ООН, признание новыхгосударств, Генеральная Ассамблея ООН, Совет Безопасности ООН, Устав ООН, правила процедуры, международное право, внешняя политика
\end{abstract}

Keywords: definition of a state, accepting practice, the UN Member States, recognition of new states, the UN General Assembly, the UN Security Council, the UN Charter, procedural rules, international law, foreign policy.

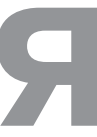

вляется ли принятие государства в качестве члена ООН равнозначным признанию этого государства?

Если мы можем признать, что в мире существуют субъекты международного права не являющиеся членами ООН, но в тоже время являющиеся государствами (Святой Престол), по простой причине возможности существования государств, либо нежелающих принимать участие в деятельности данной организации в качестве члена, либо не соответствующих требованиям гл. 2 Устава ООН, то признание в качестве члена данной организации логически закреплено исключительно за государствами (п. 1. Ст. 4 Устава ООН). Как следствие, членство в ООН не может отождествляться с понятием государства, а данная организация хоть и обладает практически полной универсальностью, с теоретической точки зрения ее универсальность все же не является абсолютной. Другими словами, государства существовали еще до того как появилась ООН, и существуют вне связи с членством в ней.

Если данный вопрос относительно прост в решении, то вопрос о том является ли прием в члены $\mathrm{OOH}$ равносильным признанию того или иного государства более сложен. Действительно, если принятие в качестве члена организации возможно исключительно в отношении государств, то что же делать если не все 
DOI: $10.7256 / 1811-9018.2013 .10 .9735$

При цитировании этой статьи сноска на доі обязательна

Международное право в XXI веке

участники мирового сообщества согласны с вопросом о том является тот или иной субъект государством и, как следствие, с тем существует ли возможность его принятия в члены организации. Или, по иному сформулировав данный вопрос мы можем его изложить следующим образом: приведет ли принятие того или иного субъекта международного права в члены ООН к его автоматическому признанию?

Данный вопрос несмотря на его кажущуюся простоту поставлен на границе юридического и политического, что и объясняет всю его сложность и не увядающую актуальность. Действительно, казалось бы что с закреплением критериев современного государства ${ }^{1}$,которые практически не оспариваются нив науке ни на практике 2 , признание государства должно быть бесспорным или механическим, так как достаточно чтобы тот или иной субъект международного права обладал собственной стабильной административной структурой, распространяющей свой суверенитет на всю свою территорию и население. Это объясняется политическим характером признания одним государством другого, что является неудовлетворительным с юридической точки зрения и заставляет нас обращаться за более убедительными критериями к признанию государств международными организациями посредством членства в них ${ }^{3}$.

Конечно же, полная тождественность между признанием того или иного субъекта международного права государством и его членством в такой международной организации как ООН вряд ли возможно. Так, логичным представляется тот факт, что если в соответствии со ст. 5 Устава ООН в отношении того или иного государства-члена будет «...приостановлено осуществление прав и привилегий, принадлежащих ему как Члену Организации...” или же в соответствии со ст. 6 Устава ООН, то или иное государство лишается статуса члена организации, то оно не перестанет быть государством. Аналогичным образом, признание государства лишь частью международного сообщества (например, квалифицированным большинством членов Генеральной ассамблей $\mathrm{OOH}$ ) - то есть при его непризнании частью мирового сообщества - не препятствует

\footnotetext{
${ }^{1}$ См. Например Конвенцию о правах и обязанностях государств, пописанную в Монтевидео в 1933 г. Montevideo Convention on the Rights and Duties of States, Signed at Montevideo, 26 December 1933, Entered into Force, 26 December 1934.

${ }^{2}$ см. например P. Bourdieu, Sur l'État: Cours au Collège de France (1989-1992), Paris, Seil, 2012.

${ }^{3}$ Право международных организаций / Под ред. И.П. Блищенко,
} А.Х. Абашидзе. - М: РУДН, 2013. его членству в ООН. В тоже время, указанные нами положения Устава ООН (ст. 4) все же свидетельствуют о наличии определённой связи между членством в ООН и признанием того или иного субъекта международного права как государства.

Стоит отметить, что не только положения Устава ООН свидетельствуют о наличии связи между членством в ООН и возможностью квалифицировать тот или иной субъект международного права как государство. Так, например ст. 2 Правил процедуры и доказывания Международного трибунала для судебного преследования лиц, ответственных за серьезные нарушения международного гуманитарного права, совершенные на территории бывшей Югославии (Международного уголовного трибунала по бывшей Югославии) 4 уточняет, что государством является “государство-член или государство не являющееся членом ООН“. Иначе говоря, если членство в ООН не является условием необходимым для признания того или иного субъекта международного права государством, то связь членства ООН с этим статусом (качеством) несомненна, так как данное положение рассматривает понятие государства в неразрывной связи с членством того или иного субъекта международного права в Организации и обуславливает возможность подачи жалобы в этот Трибунал.

Другое положение Устава ООН - п. 2, ст. 35, свидетельствует, на наш взгляд, об отсутствии тождественности между членством в ООН и признанием того или иного субъекта международного права новым государством. Действительно, данное положение устанавливает, что "...государство, которое не является Членом Организации, может довести до сведения Совета Безопасности или Генеральной Ассамблеи о любом споре, в котором оно является стороной...”. Более того, данное положение свидетельствует не только о том, что существуют государства, не являющиеся членами $\mathrm{OOH}$, но и том, что они обладают правом на обращение в данную организации в случае, если между ними и другими государствами возникает конфликт.

Вопрос о соотношении членства в ООН с признанием того или иного субъекта международного права в качестве нового государства был также разрешен Международным уголовным трибуналом по

\footnotetext{
${ }^{4}$ International Tribunal for the Prosecution of Persons Responsible for Serious Violations of

International Humanitarian Law Committed in the Territory of the former Yugoslavia since 1991. Rules of Procedure and Evidence, IT/32/ Rev. 4922 May 2013
} 
DOI: $10.7256 / 1811-9018.2013 .10 .9735$

При цитировании этой статьи сноска на dоі обязательна

\section{Право и политика $10(166) \cdot 2013$}

бывшей Югославии в деле Боснии и Герцеговины против Югославии 5 . Так, возможность принятия жалобы Боснии и Герцеговины Международным уголовным трибуналом по бывшей Югославии в первую очередь был обусловлена признанием данных образований государством, так как они могли обратиться в этот суд только в статусе последнего. Иначе говоря, Международный уголовный трибунал по бывшей Югославии в этом деле не был озабочен вопросом соотношения членства в $\mathrm{OOH}$ и признанием того или иного субъекта международного права государством. Югославия (Сербия и Черногория) требовала, чтобы трибунал отклонил жалобу этих субъектов международного права в ввиду того что они не являются государствами. Так, в частности, в заявлении Югославии было указано, что «... Федеральная республика Югославия оспаривает легитимность заявителя, так как (...) отделение Республики Босния и Герцеговина было осуществлено незаконным образом ввиду противоречия Конституции бывшей Югославской Республики и международного права» ${ }^{6}$.

Международный уголовный трибунал по бывшей Югославии отклонил данную просьбу, указав на то, что Босния является государством на основании того, что она обладает статусом члена ООН. Так, в частности трибунал указал, что Республика Босния и Герцеговина стала членом ООН в соответствии с решениями от 22 мая 1992 г., принятыми соответствующими органами данной организации - Генеральной Ассамблеей и Советом Безопасности. Трибунал также указал, что в соответствии со ст. ХІ Конвенции о предупреждении преступления геноцида и наказании за него, участником данной конвенции может стать любое государство-член $\mathrm{OOH} \mathrm{и,} \mathrm{что,} \mathrm{как} \mathrm{следствие,} \mathrm{Босния} \mathrm{и} \mathrm{Герцеговина} \mathrm{могли}$ стать участником данной конвенции и подать жалобу в Международный уголовный трибунал по бывшей Югославии. Как следствие, отметил суд, условия при которых данное государство фактически приобрело независимость не имеют значение.

Рассмотренные выводы суда свидетельствуют не только о том, что в его понимании членство в ООН равносильно признанию того или иного субъекта как нового государства, но и о том, что даже субъект фактически

\footnotetext{
${ }^{5}$ Application of the Convention on the Prevention and Punishment of the Crime of Genocide (Bosnia and Herzegovina v. Serbia and Montenegro), Judgment, I.C.J. Reports 2007, p. 43

6 "The Federal Republic of Yugoslavia contests the legitimacy of the Applicant... [The] secession of the "Republic of Bosnia-Herzegovina" [was] carried out in contravention of the Constitution of this former Yugoslav Republic, as well as the rules of international law".
}

не обладающий независимостью (суверенитетом), но являющийся членом ООН, признается им как государство лишь на том основании, что он является членом данной Организации. Иначе говоря, по мнению Трибунала принятие Боснии в ООН в качестве члена автоматически сделало бы данный субъект государством. Более того, как только тот или иной субъект становиться членом $\mathrm{OOH}$, то есть как только тот или иной субъект становиться государством, по мнению Трибунала, он располагает всеми правами принадлежащими последнему в том числе и правом стать участником различных конвенционных инструментов разработанных в рамках Организации (в данном случае речь идет о возможности Боснии присоединиться к обязательствам Конвенции о предупреждении преступления геноцида и наказании за него).

Утверждение о наличии тождественности между членством в ООН и признанием того или иного субъекта государством является вполне понятным, так как фраза ст. 4 Устава ООН гласит: «Прием в Члены Организации открыт для всех других миролюбивых государств». Непосредственная связь между членством ООН и признанием того или иного субъекта государством на основе данного положения Устава ООН идентифицируется и в доктрине международного права. Так, например, один из наших зарубежных коллег утверждает, что «... членство в ООН сегодня предполагает наличие такого качества государственности, которое уже будет сложно отрицать». Другой зарубежный автор - Шабтай Розен, также считает, что существует связь между приемом в члены ООН и признанием того или иного субъекта международного права государством, что он связывает с тем, что обязательства, которые накладываются на того или иного челна Организации, и решения, которые принимает последняя, могут быть соблюдены и исполнены лишь государством ${ }^{8}$. Данный автор также пишет: «Принятие в члены $(\mathrm{OOH})$ является...следствием двух действий - подачи заявки и ее одобрения соответствующими органами Организации, что в итоге позволяет тому или иному кандидату, став полноценным членом, располагать теми же правами и обязанностями что и другие члены ООН. Таким образом, одностороннее обращение государства в $\mathrm{OOH}$ с просьбой о принятии в члены является равносильным одностороннему выражению желания государства быть связанным обязатель-

\footnotetext{
${ }^{7}$ M. Dixon, Textbook on International Law, Oxford University Press, 2007.

${ }^{8}$ Sh. Rosenne, Essays on International Law and Practice, Martinus Nijhoff Publishers, 2007.
} 
DOI: $10.7256 / 1811-9018.2013 .10 .9735$

При цитировании этой статьи сноска на доі обязательна

Международное право в XXI веке

ствами по тому или иному международному договору. Здесь применятся принцип «обязательство возникает из согласия сторон» (exconsensus advenitvinculum). Таким образом, правильным будет сказать, что заявка о принятии в членство соответствует элементу международного (учредительного) договора который лежит в основе создания любой международной организации, в том числе и той которая формально создана актом не являющимся договором в смысле Венской конвенции. Тем не менее, сходство заявки на принятие в члены $\mathrm{OOH}$ и заявки об участии в международном соглашении ограничивается именно этим, так как заявка на принятие в членство является лишь первой стадией процесса приема в члены, которое затем должно быть оформлено решением соответствующего органа (органов) организации. Решение этого органа является решающим в данном процессе и обязательным для всех членов организации, вне зависимости от того как голосовал тот или иной член организации или даже был ли он на момент голосования членом данной организации или нет» ${ }^{9}$.

Иначе говоря, процитированный нами автор считает, что факт членства в ООН является признанием государства в качестве такового и является обязательным для всех членов этой организации. Это конечно же не означает, что факт принятия в члены ООН является изначальным условием обязательного признания данного государства всеми членами организации. Государство является государством внезависимости о того является ли оно членом ООН или нет. В тоже время другие государства не обязаны признавать то или иное государство в качестве такового и вступать с ним в какие либо отношения, однако, в то же время, им приходиться считаться с его существованием, так как они не могут его полностью игнорировать. Членство в ООН является

\footnotetext{
${ }^{9}$ Ibid. "The admission to membership is . . the consequence of the combination of the application and the favourable determination of the competent organ or organs, and upon its effectuation the State becomes a member of the organization on the same footing as all other existing members. It follows that the unilateral application to be admitted as a member has some affinity with the unilateral act by which a State expresses its consent to be bound by an existing treaty open to it. This gives partial effect to the principle ex consensus advenit vinculum. It would indeed be accurate to state that the application corresponds to the treaty element which, as seen, underlies the constituent instrument of every international organization, even one formally established by an instrument which is not a treaty within the meaning of the Vienna Conventions. But there the similarity ends, for the application is only the first stage in the process of admission, which is completed by the decision of the competent organ. That decision has dispositive effect and is binding upon every member of the organization, regardless of how it voted or even whether it was a member of the organization at the time.
}

участием государства в многостороннем международном соглашении и может быть определено как обязательство по отношению к другим государствам-членам обращаться к каждому из них как к таковому. Данное утверждение является необходимым, на наш взгляд, в связи с тем, что процедура принятия новых членов, предусматривающая, что такое принятие возможно даже при наличии лишь квалифицированного большинства Генеральной Ассамблеи ООН в две трети ее членов, предполагает, что некоторые из ее членов могут воспротивиться принятию новых членов в Организацию, но, в тоже время не могут воспрепятствовать этому (см. Правила процедуры Ген. Ассамблеи ${ }^{10}$ ). Тем не менее, им придется в дальнейшем работать с данным государством в рамках данной организации, так как оно может стать ее членом несмотря на нежелание отдельных ее членов. Иначе говоря, Устав ООН в совокупности с Правилами процедуры Генеральной Ассамблеи предполагают необходимость отношения одного государствачлена к другому члену как государству внезависимости о того признает ли оно его или нет, так как в данном вопросе не существует требования единогласного одобрения для принятия в члены организации и, как следствие, один из членов организации может быть против участия в организации какого-либо другого ее члена. В результате, в соответствии с процитированными положениями Устава ООН (гл. 2) и Правилами процедуры Генеральной Ассамблеи(Правило 136), любому члену организации приходиться действовать в отношении любого другого члена организации как в отношении государства, даже если он не признает его в качестве такового.

Нам вряд ли стоит рассматривать различные аспекты влияния признания одними или несколькими государствами какого-либо другого государства на его принятие в члены ООН, потому что данный вопрос является скорее внешнеполитическим, а не юридическим, а также потому что ему было посвящено достаточное количество работ в области международного права и политики ${ }^{11}$. В тоже время, сегодня в науке международного права все чаще можно встретить, уже не раз упомянутое нами утверждение о том, что членство в ООН предполагает

\footnotetext{
${ }^{10}$ См. Правило 136 Правил процедуры Генеральной Ассамблеи, A/520/Rev. 17

${ }^{11}$ Мингазов, Л. Х. Членство в Организации Объединенных Наций и проблема признания новых государств :Соотношение международно-правовых институтов : Автореферат диссертации на соискание ученой степени кандидата юридических наук. /Московский государственный университет им. М. В. Ломоносова. Юридический факультет. -М.,1972. -26 с.
} 
DOI: $10.7256 / 1811-9018.2013 .10 .9735$

При цитировании этой статьи сноска на dоі обязательна

\section{Право и политика $10(166) \cdot 2013$}

признание государства всеми его членами. Так, например, наш зарубежный коллега М. Хадсон, рассуждая о проекте Декларации о правах и обязанностях государств предложил закрепить в тексте положение в соответствии с которым членство в ООН станет равносильным признанию государства всеми членами Организации ${ }^{12}$.

Тем не менее, сегодня все еще существует ряд причин по которым установление тождественности между членством в ООН и признанием государства всеми членами данной организации остается невозможным. Вопервых, признание государства остается дискреционным полномочием любого государства, что непосредственно связано с его суверенитетом и посему является политическим решением. Во-вторых, ООН в связи со своим универсальным характером и, как следствие, огромным количеством государств-членов является не совсем пригодной структурой для универсального признания государств. По данному вопросу достаточно процитировать нашего зарубежного коллегу Дж. Дугарта ${ }^{13}$, который, на наш взгляд, наиболее правильно проанализировал причины, по которым членство в ООН не может быть приравнено автоматическому признанию государств-членов всеми государствами-членами данной организации. Он пишет в частности: «Основной причиной отказа от коллективного признания государства государствамичленами ООН является (...) формальность. Большинство авторов ограничиваясь рассмотрением примера из практики ООН, касающегося непризнания Израиля рядом арабских государств, констатируют что признание государств посредством членства в ООН невозможно. В поддержку данного мнения они ссылаются также на факт отказа в принятии поправки, предложенной Норвегией на Конференции в Сан-Франциско в 1945 г., которая была направлена на закрепление за ООН права коллективного признания новых государств. Как следствие, именно используя данные аргументы в науке международного права признается, что отцы-основатели ООН не желали рассматривать членство в ООН как коллективное признание новых государств. Многие авторы, которые поддерживают идею коллективного признания, отмечают, что членство в данной Организации имеет большое значение для принципа коллективного признания, но тем не менее не позволяет его имплементировать. Как следствие, мы можем рассматривать членство в $\mathrm{OOH}$

${ }^{12}$ M. O. Hudson, International Tribunals, Past and Future, Kessinger Publishing, 2008 -

${ }^{13} \mathrm{~J}$. Dugard, Recognition and the United Nations, Grotius Publications Limited, 1987. лишь как «коллективное признание в некотором смысле этого слова», «шаг на пути к закреплению принципа коллективного признанию», «аналог принципа коллективного признания», «систему сертификации, которая в принципе замещает коллективное признание», «эквивалент признания члена Организации как государства», «заменитель, практически всех аспектов признания». Некоторые авторы считают, что когда ООН достигнет полной универсальности понятие признания государства исчезнет, а членство в организации станет единственным стандартом взаимодействия государств» ${ }^{14}$.

Несмотря на такие оптимистичные заявления и на универсальную природу ООН, признание государства остается прерогативой государств, тогда как принятие в члены ООН является аналогом признания государства, но полностью не совпадает с ним. Признание одного государства другим попрежнему остается актом политической воли и выражения суверенитета признающего государства, так как остается в полной дискреции признающего государства, тогда как принятие в члены ООН является юридическим актом.

Я. Броунли считает, что «...признание является публичным действием государства, которое носит политический характер и посему какое-либо государство не может быть принуждено к признанию другого государства. Тем не менее, если какой-либо субъект обладает признаками государства, то другие государства могут испытать на себе негативные последствия в случае если они будут полностью игнорировать его существование и не соблюдать в отношении него минимальный набор принципов международного права, применяемых к межгосударственным отношениям» ${ }^{15}$.

\section{Библиография:}

1. Блищенко И.П., Абашидзе А.Х. Право международных организаций / Под ред. И.П. Блищенко, А.Х. Абашидзе. - М: РУДН, 2013.

2. Мингазов, Л. Х. Членство в Организации Объединенных Наций и проблема признания новых государств: Соотношение международно-правовых институтов: Автореферат диссертации на соискание ученой степени кандидата юридических наук. /МГУ им. М. В. Ломоносова. Юридический факультет. - М., 1972.

\footnotetext{
${ }^{14}$ Ti-Chiang Chen, The international law of recognition: with special reference to practice in Great Britain and the United States, Stevens, 1951.

${ }^{15} \mathrm{~J}$. Crawford, Brownlie's Principles of Public International Law, OUP Oxford, 2012. -
} 
DOI: $10.7256 / 1811-9018.2013 .10 .9735$

При цитировании этой статьи сноска на doi обязательна

Международное право в XXI веке

3. Bourdieu P., Sur l'État : Cours au Collège de France (1989-1992), Paris, Seil, 2012.

4. Chen, Ti-Chiang, The international law of recognition: with special reference to practice in Great Britain and the United States, Stevens, 1951.

5. Crawford J., Brownlie's Principles of Public International Law, OUP Oxford, 2012.

6. Dixon M., Textbook on International Law, Oxford University Press, 2007.

7. Dugard J., Recognition and the United Nations, Grotius Publications Limited, 1987.

8. Hudson M. O., International Tribunals, Past and Future, Kessinger Publishing, 2008.

9. Rosenne Sh., Essays on International Law and Practice, Martinus Nijhoff Publishers, 2007.

\section{References (transliteration):}

1. Blishchenko I.P., Abashidze A.Kh. Pravo mezhdunarodnykh organizatsii / Pod red. I.P. Blishchenko, A.Kh. Abashidze. - M: RUDN, 2013.
2. Mingazov, L. Kh. Chlenstvo v Organizatsii Ob'edinennykh Natsii i problema priznaniya novykh gosudarstv: Sootnoshenie mezhdunarodno-pravovykh institutov : Avtoreferat dissertatsii na soiskanie uchenoi stepeni kandidata yuridicheskikh nauk. /MGU im. M. V. Lomonosova. Yuridicheskii fakul'tet. - M.,1972.

3. Bourdieu P., Sur l'État : Cours au Collège de France (1989-1992), Paris, Seil, 2012.

4. Chen, Ti-Chiang, The international law of recognition: with special reference to practice in Great Britain and the United States, Stevens, 1951.

5. Crawford J., Brownlie's Principles of Public International Law, OUP Oxford, 2012.

6. Dixon M., Textbook on International Law, Oxford University Press, 2007.

7. Dugard J., Recognition and the United Nations, Grotius Publications Limited, 1987.

8. Hudson M. O., International Tribunals, Past and Future, Kessinger Publishing, 2008.

9. Rosenne Sh., Essays on International Law and Practice, Martinus Nijhoff Publishers, 2007. 